\title{
Assessment of early blight (A/ternaria solani) resistance in tomato using a droplet inoculation method
}

\begin{abstract}
A droplet inoculation method was used for evaluation of tomato resistance to early blight, a destructive foliar disease of tomato caused by Alternaria solani (Ellis and Martin) Sorauer. In this test method, leaflets are inoculated with small droplets of a spore suspension in either water or a $0.1 \%$ agar solution. Early blight resistance was evaluated based on lesion size. The droplet method better discriminated the level of resistance $(P<0.001)$ for a range of spore densities in comparison with the more commonly used spray inoculation method. Lesions generated by droplet inoculation at 7 days after inoculation ranged from small flecks to almost complete blight with an exponential-like distribution of lesion sizes. Significant correlations $(r=0.52$, 0.58 , and $0.63, P<0.001$ ) were observed across three glasshouse tests of 54 accessions including wild species using the droplet method. The most resistant accessions included wild species: one accession of Solanum arcanum, three accessions of Solanum peruvianum, one accession of Solanum neorickii, and one of Solanum chilense. Solanum pennellii and Solanum pimpinellifolium accessions were susceptible, whereas Solanum habrochaites and Solanum lycopersicum accessions ranged from susceptible to moderately resistant. The droplet test method is simple to apply, offers a fine discrimination of early blight resistance levels, and allows objective evaluation.
\end{abstract}

Key words Early blight - Alternaria solani . Tomato · Resistance $\cdot$ Screening method

R. Chaerani ${ }^{1} \cdot$ R. Groenwold $\cdot$ R.E. Voorrips $(\bowtie)$

Plant Research International, PO Box 16, Wageningen 6700 AA,

The Netherlands

Tel. +31-317-47-7022; Fax +31-317-41-8094

e-mail: roeland.voorrips@wur.nl

P. Stam

Laboratory of Plant Breeding, Department of Plant Sciences,

Wageningen University, Wageningen, The Netherlands

Present address:

${ }^{1}$ Indonesian Center for Agricultural Biotechnology and Genetic Resources Research and Development, Jln. Tentara Pelajar no. 3A, Bogor 16111, Indonesia

\section{Introduction}

Early blight of tomato, caused by Alternaria solani (Ellis and Martin) Sorauer, is a serious disease in warm and humid regions (Sherf and MacNab 1986) and in semiarid areas where frequent and prolonged night dew occurs (Rotem and Reichert 1964). Early blight (EB) reduces the photosynthetic area, and, in severe cases, can defoliate plants.

Cultivars highly resistant to EB are not known for cultivated tomato [Solanum lycopersicum (Peralta et al. 2005; formerly known as Lycopersicon esculentum)]. All breeding lines and released cultivars range in susceptibility from susceptible to moderately resistant (Vakalounakis 1983; Gardner 1988; Poysa and Tu 1996; Banerjee et al. 1998; Vloutoglou 1999; Gardner and Shoemaker 1999). Several wild species [Solanum habrochaites (syn. Lycopersicon hirsutum), Solanum pimpinellifolium (syn. Lycopersicon pimpinellifolium), Solanum peruvianum (syn. Lycopersicon peruvianum), and Solanum chilense (syn. Lycopersicon chilense)] have been identified as potential sources of resistance (Nash and Gardner 1988; Kalloo and Banerjee 1993; Poysa and Tu 1996; Foolad et al. 2000; Thirthamalappa and Lohithaswa 2000). Some of these, primarily S. habrochaites accession PI 126445, have been used to develop moderately resistant breeding lines (Gardner 1988; Gardner and Shoemaker 1999). Identification of additional sources of resistance could facilitate the development of resistant cultivars.

Field evaluations can identify sources of resistance, but the major drawbacks are the lengthy duration of the tests, uncontrollable environmental conditions necessary for infection, and the presence of other foliar pathogens (Locke 1948; Foolad et al. 2000; Pandey et al. 2003). Glasshouse tests using spray inoculation of a spore suspension on seedlings are widely used since the establishment of efficient screening and spore inoculum production techniques by Barksdale (1969). The EB lesions resulting from spray inoculation are scattered on the leaves so that the observer must estimate the combined area of all lesions on all leaflets 
as a percentage of the total leaf area. Disease estimates are rapid but rather subjective. Another disadvantage of the spray inoculation method is that the inoculum may not be uniformly distributed on the leaves. Furthermore, the method is not sensitive enough to discriminate moderately resistant plants from those that are susceptible (Gardner 1990).

An alternative method to obtain more precise and reliable disease readings is offered by placing individual droplets of a fungal inoculum suspension on the leaflets. This method was first introduced by Locke (1948) to find sources of resistance to EB. Detached leaflets were inoculated with a mycelial suspension in a laboratory assay, and the disease reaction was evaluated using a diagram of a graded series of lesions with known diameters (Locke 1948, 1949). Henning and Alexander (1959) used the droplet method to investigate the existence of $A$. solani races by inoculating leaflets still attached to plants. Nash and Gardner (1988) applied the method, which they called point inoculation, on a whole plant assay and measured the EB lesion diameter. EB resistance of two parents and the F1s were tested in a glasshouse. Their results correlated well with field tests, but were based only on a few genotypes.

Large numbers of accessions have never been screened in the glasshouse using the droplet inoculation method. We describe here some improvements on the method and its application to identify potential EB resistance sources in a collection of tomato accessions.

\section{Materials and methods}

Plant material and culture conditions

Tomato seeds were germinated on moistened filter paper in 90-mm-diameter petri dishes for 5-7 days in darkness at $19^{\circ} \mathrm{C}$. Germinating seeds were planted in peat soil in boxes or plastic pots. Plants were grown in a glasshouse in Wageningen, The Netherlands, at day/night temperatures of $22^{\circ} / 20^{\circ} \mathrm{C}$. Tomato accessions used in the screening experiments are listed in Table 3 . They were propagated one generation before use; where possible, inbred lines were obtained by selfing, but in the case of $S$. peruvianum, halfsib families were harvested after intercrossing five plants per accession. In cases with clear morphological differences between the five plants of the original accession, two lines or two half-sib families were included in the screening experiments.

Fungal culture and inoculum preparation

An Alternaria solani isolate obtained from infected tomato leaves in Sukabumi, West Java, Indonesia, was propagated on V8 juice agar in 90-mm-diameter petri dishes. The dishes were incubated at $21^{\circ}-22^{\circ} \mathrm{C}$ with a 12 -h diurnal period of fluorescent light for 10-17 days. The cultures were induced to sporulate as described by Barksdale (1969). The number of spores in the suspension was counted in five $10-\mu 1$ samples. The yield per plate was about $0.7-13.0 \times 10^{5}$ spores.

\section{Conditions during infection}

For the first $40 \mathrm{~h}$ immediately after inoculation, plants were incubated on a glasshouse bench lined with a wet mat and covered with a transparent plastic tunnel. Periodic misting to maintain high humidity was supplied from a humidifier. After the initial incubation, each side of the tunnel was opened, and the humidifier was turned off for $8 \mathrm{~h}$ during the day to allow the plant surface to dry. Minimum light intensity in the plastic tunnel was approximately $14 \mu \mathrm{mol} \mathrm{m}^{-2} \mathrm{~s}^{-1}$; when necessary, daylight was supplemented with light from high-pressure sodium vapor lamps $\left(17 \mu \mathrm{mol} \mathrm{m}^{-2} \mathrm{~s}^{-1}\right)$ for $16 \mathrm{hday}^{-1}$. The temperature and relative humidity were recorded with a thermohygrograph.

Effect of spore concentration on early blight severity with two inoculation methods

One moderately resistant (FT94-978; 99-213) and one susceptible (HRC90.145) S. lycopersicum line were grown for 3 weeks on peat soil in boxes of $34 \times 29.5 \times 4 \mathrm{~cm}$. Two inoculation methods, the droplet and the standard spray inoculation methods, were compared. Spore density was varied $\left(0,1,2,4,10\right.$, and $20 \times 10^{3} \mathrm{ml}^{-1}$ water $)$ to find the most discriminating level.

Plants inoculated using the droplet method were raised in boxes of 12 plants, with two rows of three plants of each genotype. A single drop $(10 \mu \mathrm{l})$ of a spore suspension was placed on an interveinal space of the upper surface of three apical leaflets. The two first expanded leaves were used. The six spore concentrations were randomized over the six plants of each genotype in each box. The experiment was replicated over three boxes.

In the spray inoculation treatment, boxes contained four rows of four plants, with the two genotypes in alternating rows. Each pair of rows was sprayed with one spore concentration until runoff. The experiment was replicated four times ( 24 boxes).

The boxes were covered with a transparent lid and placed in the tunnel with intermittent misting for $15 \mathrm{~min}$ at $45-\mathrm{min}$ intervals. After the first $24 \mathrm{~h}$, the lids were removed. The temperature during the day was $20^{\circ}-27^{\circ} \mathrm{C}$ and during the night was $16^{\circ}-24^{\circ} \mathrm{C}$. The relative humidity ranged from $40 \%$ to $72 \%$ during the day and from $85 \%$ to $100 \%$ during the night. Symptom evaluations were done 7 days after inoculation. Length and width of lesions after droplet inoculation were measured. EB severity on each leaf of the sprayed plants was recorded on a scale of 0 to 5 , where $0=$ no visible lesions on leaf; $1=$ up to $10 \%$ leaf area affected; $2=11 \%-$ $25 \% ; 3=26 \%-50 \% ; 4=51 \%-75 \%$; and $5=$ more than $75 \%$ leaf area affected or leaf abscised (Vakalounakis 1983). Leaves that were not completely unfurled during the inoculation were not assessed. The disease scales were converted 
into percentage of EB index (PEBI) for each plant using the following formula (Pandey et al. 2003):

$$
\text { PEBI }=\frac{\text { sum of all ratings }}{\text { no. of leaves sampled } \times \text { maximum }} \times 100
$$

Resistance reaction of selected accessions with two inoculation methods in the glasshouse

The repeatability of the droplet inoculation method in determining early blight resistance in a wider range of accessions was compared with the spray inoculation method. Nine accessions including wild species that were found to differ in mean EB lesion size in preliminary experiments were planted in pots and inoculated at 6 weeks after germination.

For spray inoculation, plants were sprayed with spores in water until runoff. For droplet inoculations, a single drop $(10 \mu \mathrm{l})$ of $0.1 \%$ agar solution with $10^{4}$ spores $\mathrm{ml}^{-1}$ was placed on an interveinal area of three apical leaflets of the four topmost expanded leaves. With agar, the droplets were more likely to adhere to the leaves. The spore concentration of $10^{4}$ spores $\mathrm{ml}^{-1}$ was selected based on the most optimal inoculum level found for the spray inoculation (see Results), was used for both inoculation methods. Two plants of each accession were tested in three replications for the droplet inoculation and four replications for the spray inoculation. Noninoculated plants were used as controls for both inoculation methods. The plants were placed in a humidified tunnel directly after inoculation and received periodic misting for $45 \mathrm{~s}$ at 8 -min intervals. Daytime temperatures ranged from $25^{\circ}$ to $27^{\circ} \mathrm{C}$ and nighttime temperatures from $20^{\circ}$ to $22^{\circ} \mathrm{C}$. The relative humidity ranged from $59 \%$ to $69 \%$ during the day and was $98 \%$ during the night. Disease reactions were recorded at 7 days after inoculation using the procedure for the respective inoculation methods as previously described.

\section{Glasshouse screening of tomato accessions}

\section{Glasshouse screening 2001 (autumn)}

Forty-one accessions including wild species were tested (Table 3; GH I and GH II). For 11 accessions, two or three lines or half-sib families were tested because the original accession was not morphologically uniform. The plants were raised in boxes of $34 \times 29.5 \times 4 \mathrm{~cm}$. Each box contained 12 plots of two plants of 12 different accessions, which were randomized in the boxes. The plants were inoculated using the droplet method at 3 weeks after sowing, when most of them had two fully expanded leaves. Boxes were closed with transparent lids for $24 \mathrm{~h}$ and placed in the tunnel. The misting period was $15 \mathrm{minh}^{-1}$. The length and the perpendicular width of lesions were recorded 7 days after inoculation. The experiment was replicated five times at weekly intervals; each replicate was treated as a block in the statistical analysis.
In the first two replicates, the three apical leaflets of the two basal leaves of two plants of each accession were inoculated with $2 \times 10^{4}$ spores $\mathrm{ml}^{-1}$ water. However, the basal leaves of some wild species, both with and without lesions were lost earlier (3 days after inoculation) than those of the cultivated tomato, possibly due to faster development and senescence. Early senescence and defoliation were accelerated by inoculation with the pathogen. On some susceptible accessions, lesions expanded rapidly and caused early development of blight. Because of these problems, the droplet inoculation procedures were modified in the subsequent replicates. These first two replicates were treated as a separate experiment, designated as "glasshouse test I" (GH I).

In the subsequent three replicates (GH II) the three apical leaflets of the four topmost leaves were inoculated to achieve a more uniform physiological age of leaves, and a lower inoculum density $\left(4 \times 10^{3}\right.$ spores $\mathrm{ml}^{-1}$ water $)$ was used to prevent blight symptoms from developing too rapidly. Three replicates in time were performed. In the first replicate of GH II, some accessions were represented by less than two plants due to poor germination.

Temperatures ranged from $20^{\circ}$ to $23^{\circ} \mathrm{C}$ during the day and from $17^{\circ}$ to $19^{\circ} \mathrm{C}$ during the night. Relative humidity ranged from $43 \%$ to $64 \%$ during the day and from $97 \%$ to $100 \%$ during the night.

\section{Glasshouse screening 2002 (summer)}

The same 41 accessions were retested together with 13 additional accessions in five replicated tests, performed at weekly intervals (Table 3; GH III). Plants were grown in 12-cm-diameter pots (one seedling per pot) to facilitate inoculation and evaluation. Four weeks after sowing, plants were inoculated at the three apical leaflets of the four topmost expanded leaves with a single drop $(10 \mu \mathrm{l})$ of $0.1 \%$ agar solution carrying $10^{4}$ spores $\mathrm{ml}^{-1}$. Each replicate included one plant of each accession. Control plants, one plant of each species, which were inoculated with agar solution without spores, were also included in the tests. Plants were placed in a tunnel and exposed to a fine mist for $45 \mathrm{~s}$ to $1 \mathrm{~min}$ at intervals of $6-8 \mathrm{~min}$. Five replicate tests were performed during the season at 1 -week intervals. The length and the perpendicular width of the lesions were measured at 7 days after inoculation. Day temperatures ranged from $22^{\circ}$ to $27^{\circ} \mathrm{C}$, night temperatures from $20^{\circ}$ to $22^{\circ} \mathrm{C}$. Relative humidity ranged from $40 \%$ to $66 \%$ during the day and from $91 \%$ to $93 \%$ during the night.

\section{Experimental design and statistical analyses}

The elementary data consisted of lesion size (length $\times$ width) for the droplet inoculation, and PEBI per plant for the spray inoculation. Heterogeneity in the variances was observed in the data from both inoculation methods. Logarithmic and arcsine-square root transformation was applied before statistical analysis to the lesion size and PEBI data, respectively, to stabilize the variances. 
Table 1. Means of disease parameters after droplet inoculation (lesion size) and spray inoculation (percentage of early blight index, PEBI)

\begin{tabular}{|c|c|c|c|c|c|c|}
\hline \multirow{2}{*}{$\begin{array}{l}\text { Spore density } \\
\left(\times 10^{3} \mathrm{ml}^{-1}\right)\end{array}$} & \multicolumn{2}{|c|}{ Lesion size mean $\left(\mathrm{mm}^{2}\right)^{\mathrm{a}}$} & \multirow[t]{2}{*}{$t$ value } & \multicolumn{2}{|c|}{ PEBI mean $(\%)^{\mathrm{b}}$} & \multirow[t]{2}{*}{$t$ value } \\
\hline & HRC90.145 & FT94-978; 99-213 & & HRC90.145 & FT94-978; 99-213 & \\
\hline 1 & 29.92 & 10.50 & $2.16^{*}$ & 18.12 & 14.68 & 1.63 \\
\hline 2 & 86.50 & 16.60 & $4.38 * * * *$ & 28.93 & 19.23 & $2.61 *$ \\
\hline 4 & 108.64 & 37.93 & $5.24 * * * *$ & 44.88 & 27.64 & $2.53 *$ \\
\hline 10 & 135.83 & 53.09 & $4.16 * * * *$ & 74.91 & 53.31 & $4.16^{* * * * *}$ \\
\hline 20 & 213.80 & 80.91 & $6.18 * * * *$ & 61.62 & 75.21 & $2.98 * * *$ \\
\hline
\end{tabular}

$* P<0.05 ; * * P<0.01 ; * * * P<0.005 ; * * * * P<0.001$

${ }^{a}$ Average of three replicates of 18 leaflets each $(6$ leaflets $\times 3$ plants); values are back transformations of $\log (x)$

${ }^{\mathrm{b}}$ Average of four replicates of four plants each; values are back transformations of arcsine $[\sqrt{(x / 100)}]$

Table 2. Mean early blight lesion size and percentage of early blight index (PEBI) of nine selected accessions

\begin{tabular}{llcl}
\hline Species & Accessions & Lesion size $\left(\mathrm{mm}^{2}\right)^{\mathrm{a}}$ & PEBI $^{\mathrm{b}}$ \\
\hline S. peruvianum & PE44 & $1.19 \mathrm{a}$ & $67.43 \mathrm{abc}$ \\
S. peruvianum & PE33 & $6.67 \mathrm{~b}$ & $59.03 \mathrm{a}$ \\
S. lycopersicum & HRC90.158 & $7.73 \mathrm{bc}$ & $66.28 \mathrm{abc}$ \\
S. pimpinellifolium & G1.1554 & $12.59 \mathrm{~cd}$ & $86.69 \mathrm{~cd}$ \\
S. lycopersicum & NC EBR-4 & $15.07 \mathrm{~d}$ & $62.43 \mathrm{ab}$ \\
S. habrochaites & G1.1561 & $15.21 \mathrm{~d}$ & $84.98 \mathrm{bcd}$ \\
S. habrochaites & $864086-2 ;$ PI272745 & $29.72 \mathrm{e}$ & $97.71 \mathrm{~d}$ \\
S. habrochaites & PE36 & $40.18 \mathrm{e}$ & $60.40 \mathrm{ab}$ \\
S. lycopersicum & FT97-515; 99-214 & $45.92 \mathrm{e}$ & $90.86 \mathrm{~d}$
\end{tabular}

${ }^{\mathrm{a}}$ Length $\times$ width measured 7 days after inoculation. Each value is an average of three replicates of 24 leaflets ( 3 leaflets $\times 4$ leaves $\times 2$ plants); data are back transformations of $\log (x)$. Values within a column followed by the same letters are not significantly different at $P=0.05$

${ }^{\mathrm{b}}$ Based on individual leaf scores: $0=$ no visible lesions on leaves; $1=$ up to $10 \%$ leaf area affected; $2=11 \%-25 \% ; 3=26 \%-50 \% ; 4=51 \%-75 \%$; and $5=$ more than $75 \%$ leaf area affected or leaf shed. Each value is an average of four replicates of two plants; data are back transformation of arcsine $[\sqrt{(x / 100)}]$

Student's $t$-test was performed for the data from the spore concentration experiment to compare means. All other experimental data were analyzed by analysis of variance (ANOVA) as a randomized complete block design. Mean separations were done by means of least significant difference (LSD) tests $(P \leq 0.05)$. GH II was analyzed using the unbalanced treatment structure procedure of ANOVA because of the unequal number of plants per block and per accession. All analyses were done using the GenStat 6 statistical package (Payne et al. 2002).

\section{Results}

The effect of spore concentration on EB severity under two inoculation methods

EB lesions resulting from both the droplet and spray inoculations appeared within 3 days after inoculation. Some droplet inoculations failed to yield substantial lesions; either small spots ( $\leq 1 \mathrm{~mm}$ in diameter) formed, or no symptoms developed. This was observed for both accessions. Symptomless inoculations were scored as missing values.

With both inoculation methods, FT94-978; 99-213 (moderately resistant) developed significantly smaller lesions or lower PEBI than HRC90.145 (susceptible) at all spore concentrations, except for PEBI at $20 \times 10^{3} \mathrm{ml}^{-1}$ (Table 1). At all concentrations, the droplet method better discriminated the resistance level than the spray method, as indicated by higher and more significant $t$ values $(P<0.001)$. The most significant difference in PEBI between FT94-978; 99-213 and HRC90.145 was observed at a spore concentration of $10^{4} \mathrm{ml}^{-1}$, while the differences were highly significant at all concentrations above $10^{3} \mathrm{ml}^{-1}$ for the droplet inoculation method.

Resistance reaction of selected accessions with two inoculation methods in glasshouse tests

The comparison of the droplet and spray inoculations was expanded to a set of nine accessions representing four tomato species, which from preliminary experiments were known to represent large differences in EB resistance. The wild accessions occasionally developed spontaneous blisters or necroses under glasshouse conditions. When EB developed on S. habrochaites leaves with necroses, the lesions would expand rapidly and result in severe blight symptom, complicating the measurement of lesion size. Leaflets with blight symptoms so severe that lesion size could not be measured were scored as missing values.

The droplet method allowed a better separation of accessions than the spray inoculation method (Table 2) in accordance with the results of the spore concentration 
Fig. 1A-C. Frequency distribution of lesion sizes on droplet-inoculated plants in three groups of three accessions: $\mathbf{A}$ resistant, $\mathbf{B}$ moderately resistant, and $\mathbf{C}$ susceptible accessions

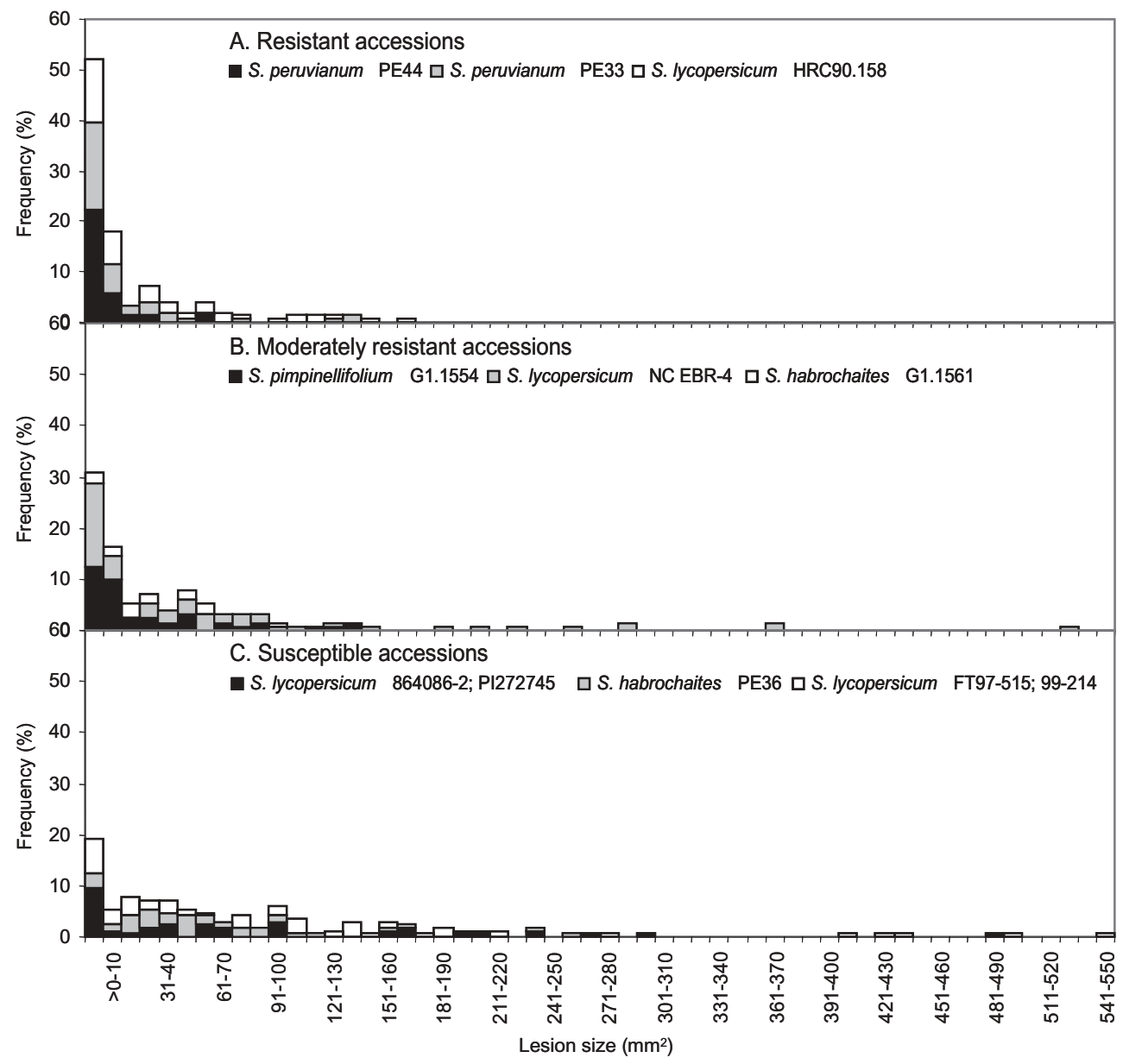

experiment. Accession reactions with the two inoculation methods were not significantly correlated ( $r=0.44, P>0.2)$. $S$. habrochaites PE36 had inconsistent results between the two inoculation methods: it was ranked as susceptible with the droplet method but resistant with the spray method. Occasional spontaneous necroses on this accession inoculated with the droplet method exacerbated EB lesions. Excluding this accession from the analysis increased the correlation considerably $(r=0.66)$.

EB lesions on petioles were observed on sprayed plants. Large, sunken lesions on petioles often caused loss of the leaf and thus raised the PEBI of accessions that had small leaf lesions when inoculated by the droplet method. The petiole lesions were generated randomly because the spray inoculation was not purposely directed to petioles.

\section{Lesion size distribution}

Inoculations using the droplet method did not always develop into a noticeable lesion, irrespective of the level of resistance of a plant. We first assumed that the spores dried out before successfully penetrating the host tissue during the initial hours of incubation in the tunnel. However, incorporation of $0.1 \%$ agar solution into the spore suspension, which immobilized the droplets and slowed evaporation, did not influence the probability of lesion formation.
After grouping the nine accessions into three categories (resistant, moderately resistant, and susceptible), an exponential-like distribution of lesion sizes was observed in each group (Fig. 1). The more resistant accessions had a higher frequency of small lesions, a lower frequency of larger lesions, and a lower mean lesion size. Symptomless leaflets were observed with an average of $0.9 \%, 7 \%$, and $18.2 \%$ for susceptible, intermediate, and resistant accessions, respectively; for flecks $\left(\leq 1 \mathrm{~mm}^{2}\right)$, these frequencies were $2 \%, 9 \%$, and $17 \%$. In a microscopic evaluation of leaflets with flecks after staining with lactophenol-cotton blue, infection was evident by the presence of germ tube penetration, but mycelial proliferation was absent. An exponential-like distribution of lesion size was also observed for plants inoculated by spraying (data not shown).

\section{Glasshouse screenings}

Lesions near leaf veins of the susceptible S. lycopersicum accessions were often accompanied by smaller lesions of angular shape without concentric rings along the vein and at the distal ends of the vein. These smaller lesions rapidly expanded and eventually merged with the primary lesions, resulting in almost completely blighted leaves before lesion measurement at 7 days after inoculation. Flecks, which did not further expand, and symptomless inoculations were 
again observed on all tested accessions. Leaflets with severe blight and those without appreciable lesions were scored as missing values.

The means of the lesion sizes from each glasshouse test were weighted with the reciprocals of the variances to obtain overall accession mean values. This adjustment was necessary since variances of the means among the three tests were unequal. After calculating the weighted average, we observed a continuous range of resistance levels, from highly susceptible ( $S$. pennellii LA716, average lesion size $\left.107.65 \mathrm{~mm}^{2}\right)$ to highly resistant $(S$. arcanum LA2157, $1.40 \mathrm{~mm}^{2}$ ) (Table 3 ). However, no complete resistance was found. Among the glasshouse tests, significant correlations were observed $(P<0.001)$, with correlation coefficients of 0.58 (between GH I and II), 0.52 (GH I and III), and 0.63 (GH II and III). Most of the resistant accessions belonged to wild species ( $S$. arcanum, $S$. peruvianum, $S$. neorickii, and $S$. chilense). However, both susceptible and moderately resistant $S$. habrochaites accessions were found, and other wild accessions belonging to $S$. pimpinellifolium and especially $S$. pennellii were susceptible. Among different lines of the previously reported moderately resistant accession HRC91.341 (Poysa and Tu 1996), there were significant differences in EB lesion sizes. One line of this accession was susceptible in $\mathrm{GH}$ II but resistant or moderately resistant in $\mathrm{GH}$ I and GH III, while the other line was resistant in all three tests. Lines derived from NC EBR-2 and NC EBR-3 also had a different reaction in GH II compared with GH I and GH III.

Single lesions resulting from the droplet inoculation permitted detailed observation of lesion phenotypes. Necrotic lesions on S. neorickii (syn. L. parviflorum), some accessions of $S$. habrochaites and $S$. peruvianum, and S. lycopersicum NC EBR-6 were surrounded by narrow chlorotic halos, whereas those on $S$. pennellii, S. chilense, and other accessions of $S$. habrochaites and $S$. peruvianum were not accompanied by chlorotic halos. S. pimpinellifolium and other S. lycopersicum genotypes had a range of intermediate to wide halos. The extent of the halos did not seem to correlate with the size of the necrotic lesions (data not shown).

\section{Discussion}

The droplet inoculation method offers better discrimination among accessions than the spray method. This was observed in the spore concentration experiment and in the nine-accession experiment. Variance of lesion size increased with increasing means in both experiments. Distribution of lesion sizes seemed to be exponential, with many small lesions and few large ones. This trend was observed at all levels of resistance.

The discrepancy between the results of the droplet and spray methods can partly be explained by two factors. First, some wild species developed severe necroses in the glasshouse experiment even without inoculation. After spray inoculation, these necroses were often indistinguishable from EB lesions, whereas after droplet inoculation they were simply recognized and treated as missing values. Sec- ond, spray inoculation may lead to random leaf shedding due to petiole lesions and therefore erratic, high symptom scores. The droplet method offers a possibility to test the effect of petiole lesions in a controlled way.

Across the three glasshouse screenings, significant correlations were observed. GH II and GH III yielded a better separation than GH I. Also the correlation between GH II and GH III was higher than that between GH I and the other two tests. This may be due to: (1) the lower number of observations in GH I, (2) the higher inoculum density in $\mathrm{GH}$ I, and (3) the difference in the selection of leaves between GH I and the other two tests. We used a lower inoculum concentration (40 to 200 spores per droplet) in the glasshouse screenings but observed overall larger lesion sizes than Nash and Gardner (1988) who applied more inoculum (500 to 750 spores per droplet) on basal leaves. This indicates that our tests were performed in near-optimal conditions for infection and disease development. Another difference between our work and the study of Nash and Gardner (1988) was that they selected one lesion per plant to be measured, whereas we measured all inoculations without selection. As a result, we observed a large range of lesion types, from small lesions ( $\leq 1 \mathrm{~mm}$ in diameter) to almost blighted leaflets and also symptomless leaflets within the same accession. Small lesions ( $\leq 1 \mathrm{~mm}$ in diameter) occurred on all genotypes, but their frequency corresponded with the resistance level. This was indicated by a high correlation between lesion size and the percentage of small lesions, most notably in GH II and GH III where a lower spore concentration was applied: $r=-0.73$ (GH II, $P<0.001)$ and $r=-0.77$ (GH III, $P<0.001)$.

Variability in pathogenicity of $A$. solani isolates has been widely described (Bonde 1929; Henning and Alexander 1959; Rotem 1966), but no evidence has been presented for the existence of pathological races. The results of our study, in which we used a single highly pathogenic Indonesian isolate, can therefore be expected to be representative for other Indonesian isolates as well.

The droplet inoculation method is simple to apply and allows an objective evaluation of EB severity. The method has been used to evaluate $\mathrm{EB}$ resistance components (O'Leary and Shoemaker 1983). Single lesions created by the droplet method allow detailed observation of lesion phenotype such as differential formation of halos among genotypes. The importance of the chlorotic halo as an indicator of resistance has not been studied so far. Improvements of the method have been made by incorporating agar into the spore suspension and the use of upper leaves as opposed to the bottom leaves.

The considerable amount of time required to measure lesions may make this method less attractive for largescale screenings, but this problem can be circumvented by determining the percentage of small lesions. The described advantages of the droplet inoculation method make this the method of choice where a fine discrimination of resistance level and accurate quantitative data are required, for example, in quantitative trait locus studies of resistance or in assessing breeding material during advanced backcross programs. 
Table 3. Early blight lesion sizes of Lycopersicon accessions in glasshouse tests

\begin{tabular}{|c|c|c|c|c|c|c|}
\hline Species & Accessions & Source $^{\mathrm{a}}$ & $\mathrm{GH} \mathrm{I}^{\mathrm{b}, \mathrm{c}}$ & $\mathrm{GH} \mathrm{II}{ }^{\mathrm{d}}$ & $\mathrm{GH} \mathrm{III}{ }^{\mathrm{e}}$ & Weighted average $\mathrm{f}^{\mathrm{f}}$ \\
\hline Solanum arcanum & LA2157 & 1 & NT & NT & $1.40 \mathrm{a}$ & 1.40 \\
\hline S. peruvianum & PE44 & 4 & NT & NT & $1.46 \mathrm{ab}$ & 1.46 \\
\hline S. peruvianum & PI 390665 & 4 & NT & NT & $4.07 \mathrm{c}-\mathrm{h}$ & 4.07 \\
\hline S. peruvianum & PE33 & 4 & $11.38 \mathrm{a}$ & $1.54 \mathrm{a}$ & $3.30 \mathrm{c}-\mathrm{f}$ & 6.23 \\
\hline S. neorickii & G1.1601 & 2 & NT & NT & $6.68 \mathrm{~g}-\mathrm{m}$ & 6.68 \\
\hline S. chilense & G1.1556 & 2 & NT & NT & $6.68 \mathrm{~g}-\mathrm{m}$ & 6.68 \\
\hline S. lycopersicum & NC EBR-6 & 3 & $16.90 \mathrm{ab}$ & $2.59 \mathrm{a}-\mathrm{d}$ & $5.02 \mathrm{~d}-\mathrm{k}$ & 9.56 \\
\hline S. lycopersicum & NC EBR-6 & 3 & $17.10 \mathrm{ab}$ & $4.56 \mathrm{a}-\mathrm{i}$ & $2.61 \mathrm{bc}$ & 10.49 \\
\hline S. lycopersicum & HRC86.320 & 4 & $24.27 \mathrm{a}-\mathrm{d}$ & $1.57 \mathrm{a}$ & $4.32 c-1$ & 10.61 \\
\hline S. lycopersicum & cv. Santacruz & 6 & NT & NT & $11.67 \mathrm{~m}-\mathrm{p}$ & 11.67 \\
\hline S. habrochaites & LA2650 & 4 & $18.58 \mathrm{ab}$ & $3.60 \mathrm{a}-\mathrm{g}$ & $16.79 \mathrm{p}-\mathrm{u}$ & 12.24 \\
\hline S. lycopersicum & HRC90.159 & 4 & $25.82 \mathrm{a}-\mathrm{d}$ & $2.92 \mathrm{a}-\mathrm{e}$ & $3.16 \mathrm{c}-\mathrm{f}$ & 12.56 \\
\hline S. lycopersicum & HRC86.320 & 4 & $32.36 \mathrm{a}-\mathrm{e}$ & $2.06 \mathrm{ab}$ & $2.93 \mathrm{~cd}$ & 13.29 \\
\hline S. habrochaites & PE36 & 4 & $31.48 \mathrm{a}-\mathrm{e}$ & $2.34 \mathrm{a}-\mathrm{c}$ & $10.45 \mathrm{~m}-\mathrm{p}$ & 15.00 \\
\hline S. peruvianum & PI390665 & 4 & $16.94 \mathrm{ab}$ & $11.00 \mathrm{f}-\mathrm{k}$ & $16.52 \mathrm{p}-\mathrm{u}$ & 15.19 \\
\hline S. lycopersicum & HRC90.159 & 4 & $30.55 \mathrm{a}-\mathrm{e}$ & $3.90 \mathrm{a}-\mathrm{i}$ & $4.84 \mathrm{~d}-\mathrm{j}$ & 15.65 \\
\hline S. lycopersicum & HRC91.341 & 4 & $30.97 \mathrm{a}-\mathrm{e}$ & $4.62 \mathrm{a}-\mathrm{j}$ & $4.56 \mathrm{c}-1$ & 16.40 \\
\hline S. lycopersicum & NC EBR-1 & 3 & $28.91 \mathrm{a}-\mathrm{e}$ & $4.73 a-j$ & $10.69 \mathrm{~m}-\mathrm{p}$ & 16.94 \\
\hline S. lycopersicum & NC EBR-3 & 3 & $22.49 \mathrm{a}-\mathrm{d}$ & $9.59 \mathrm{e}-\mathrm{k}$ & $7.59 \mathrm{i}-\mathrm{n}$ & 16.97 \\
\hline S. lycopersicum & HRC90.190 & 4 & $32.58 \mathrm{a}-\mathrm{e}$ & $4.98 \mathrm{a}-\mathrm{j}$ & $4.82 \mathrm{~d}-\mathrm{j}$ & 17.36 \\
\hline S. peruvianum & PI270435 & 4 & NT & NT & $17.50 \mathrm{p}-\mathrm{u}$ & 17.50 \\
\hline S. lycopersicum & cv. Sufan n.1 & 6 & NT & NT & $17.54 \mathrm{p}-\mathrm{u}$ & 17.54 \\
\hline S. habrochaites & LA1777 & 2 & NT & NT & $17.54 \mathrm{p}-\mathrm{u}$ & 17.54 \\
\hline S. lycopersicum & NC EBR-2 & 3 & $21.43 \mathrm{a}-\mathrm{c}$ & $15.10 \mathrm{jk}$ & $10.401-p$ & 18.46 \\
\hline S. lycopersicum & NC EBR-5 & 3 & $42.46 \mathrm{~b}-\mathrm{e}$ & $3.10 \mathrm{a}-\mathrm{f}$ & $5.73 \mathrm{f}-1$ & 18.67 \\
\hline S. lycopersicum & HRC86.329 & 4 & $36.39 \mathrm{a}-\mathrm{e}$ & $3.71 \mathrm{a}-\mathrm{h}$ & $12.94 \mathrm{n}-\mathrm{r}$ & 18.88 \\
\hline S. lycopersicum & HRC86.329 & 4 & $32.66 \mathrm{a}-\mathrm{e}$ & $5.16 \mathrm{a}-\mathrm{j}$ & $14.16 \mathrm{o}-\mathrm{s}$ & 19.23 \\
\hline S. lycopersicum & HRC90.157 & 4 & $30.76 \mathrm{a}-\mathrm{e}$ & $8.24 \mathrm{c}-\mathrm{k}$ & $3.83 \mathrm{c}-\mathrm{g}$ & 19.28 \\
\hline S. lycopersicum & HRC86.321 & 4 & $41.88 \mathrm{~b}-\mathrm{e}$ & $4.00 \mathrm{a}-\mathrm{i}$ & $5.33 \mathrm{e}-\mathrm{k}$ & 19.60 \\
\hline S. lycopersicum & HRC 90.159 & 4 & $39.08 \mathrm{a}-\mathrm{e}$ & $5.93 \mathrm{~b}-\mathrm{k}$ & $3.12 \mathrm{c}-\mathrm{e}$ & 19.72 \\
\hline S. lycopersicum & NC EBR-3 & 3 & $33.50 \mathrm{a}-\mathrm{e}$ & $6.04 \mathrm{~b}-\mathrm{k}$ & NT & 20.34 \\
\hline S. lycopersicum & HRC90.157 & 4 & $41.40 \mathrm{~b}-\mathrm{e}$ & $4.33 \mathrm{a}-\mathrm{i}$ & $8.36 \mathrm{j}-\mathrm{o}$ & 20.60 \\
\hline S. lycopersicum & FT94-978; 99-213 & 5 & $39.72 \mathrm{a}-\mathrm{e}$ & $4.60 \mathrm{a}-\mathrm{j}$ & $9.731-p$ & 20.62 \\
\hline S. lycopersicum & NC EBR-4 & 3 & $36.90 \mathrm{a}-\mathrm{e}$ & $6.50 \mathrm{~b}-\mathrm{k}$ & $15.63 \mathrm{p}-\mathrm{t}$ & 22.50 \\
\hline S. lycopersicum & FT94-968; 99-212 & 5 & $33.11 \mathrm{a}-\mathrm{e}$ & $10.80 \mathrm{f}-\mathrm{k}$ & $11.35 \mathrm{~m}-\mathrm{p}$ & 22.86 \\
\hline S. habrochaites & G1.1561 & 2 & $42.95 \mathrm{~b}-\mathrm{e}$ & $6.67 \mathrm{~b}-\mathrm{k}$ & $7.62 \mathrm{i}-\mathrm{n}$ & 23.33 \\
\hline S. lycopersicum & HRC91.341 & 4 & $34.28 \mathrm{a}-\mathrm{e}$ & $12.80 \mathrm{~g}-\mathrm{k}$ & $7.76 \mathrm{i}-\mathrm{n}$ & 23.63 \\
\hline S. lycopersicum & FT97-515; 99-214 & 5 & $40.18 \mathrm{~b}-\mathrm{e}$ & $6.38 \mathrm{~b}-\mathrm{k}$ & $17.50 \mathrm{p}-\mathrm{u}$ & 23.69 \\
\hline S. lycopersicum & FT94-978; 99-213 & 5 & $42.07 \mathrm{~b}-\mathrm{e}$ & $7.80 \mathrm{c}-\mathrm{k}$ & $9.04 \mathrm{k}-\mathrm{p}$ & 24.27 \\
\hline S. lycopersicum & cv. Allround & 1 & NT & NT & $24.32 \mathrm{~s}-\mathrm{u}$ & 24.32 \\
\hline S. pimpinellifolium & G1.1554 & 1 & $47.53 \mathrm{~b}-\mathrm{e}$ & $8.59 \mathrm{~d}-\mathrm{k}$ & $6.75 \mathrm{~g}-\mathrm{m}$ & 24.70 \\
\hline S. lycopersicum & HRC90.158 & 4 & $49.66 \mathrm{~b}-\mathrm{e}$ & $7.24 \mathrm{~b}-\mathrm{k}$ & $4.60 \mathrm{c}-\mathrm{j}$ & 25.13 \\
\hline S. lycopersicum & NC EBR-2 & 3 & $39.36 \mathrm{a}-\mathrm{e}$ & $13.20 \mathrm{~h}-\mathrm{k}$ & $10.211-\mathrm{p}$ & 26.73 \\
\hline S. lycopersicum & PI79532 & 6 & NT & NT & $26.98 \mathrm{t}-\mathrm{v}$ & 26.98 \\
\hline S. lycopersicum & FT94-968; 99-212 & 4 & $48.19 \mathrm{~b}-\mathrm{e}$ & $9.57 \mathrm{e}-\mathrm{k}$ & $9.771-\mathrm{p}$ & 28.15 \\
\hline S. lycopersicum & cv. Vogliotti & 6 & NT & NT & 29.17 uv & 29.17 \\
\hline S. lycopersicum & HRC89.302 & 4 & $44.26 \mathrm{~b}-\mathrm{e}$ & $12.20 \mathrm{~g}-\mathrm{k}$ & $21.04 \mathrm{q}-\mathrm{u}$ & 30.15 \\
\hline S. lycopersicum & 864084-2; PI 273048 & 5 & $68.39 \mathrm{c}-\mathrm{e}$ & $12.10 \mathrm{~g}-\mathrm{k}$ & $7.05 \mathrm{~h}-\mathrm{m}$ & 36.63 \\
\hline S. lycopersicum & HRC89.302 & 4 & $53.33 \mathrm{~b}-\mathrm{e}$ & $16.40 \mathrm{jk}$ & $21.09 \mathrm{r}-\mathrm{u}$ & 36.74 \\
\hline S. lycopersicum & cv. Moneymaker & 1 & $75.34 \mathrm{de}$ & $12.40 \mathrm{~g}-\mathrm{k}$ & $17.62 \mathrm{p}-\mathrm{u}$ & 42.52 \\
\hline S. lycopersicum & HRC86.327 & 4 & $72.11 \mathrm{c}-\mathrm{e}$ & $13.70 \mathrm{l}-\mathrm{k}$ & $45.08 \mathrm{v}$ & 45.88 \\
\hline S. lycopersicum & HRC90.145 & 4 & $71.45 \mathrm{c}-\mathrm{e}$ & $20.50 \mathrm{k}$ & $28.84 \mathrm{uv}$ & 48.49 \\
\hline S. lycopersicum & 864086-2; PI 272745 & 5 & $94.84 \mathrm{e}$ & $18.80 \mathrm{k}$ & $45.08 \mathrm{v}$ & 59.49 \\
\hline S. pennellii & LA716 & 1 & NT & NT & $107.65 \mathrm{w}$ & 107.65 \\
\hline
\end{tabular}

Lesion sizes are given in units of $\mathrm{mm}^{2}$ (length $\times$ width) measured 7 days after inoculation. Data are back transformations of $\log (x)$

NT, Not tested

a 1, Plant Research International, Wageningen, The Netherlands; 2, Dr. P. Lindhout, Laboratory of Plant Breeding, Wageningen University, The Netherlands; 3, Dr. R.G. Gardner, North Carolina Agricultural Research Institute, North Carolina State University, Raleigh, North Carolina, USA; 4, Dr. V. Poysa, Agriculture and Agri-Food Canada, Harrow Research Center, Harrow, Ontario, Canada; 5, Prof. M. Mutschler, Department of Plant Breeding, Cornell University, Ithaca, New York, USA; 6, Nunhems Zaden BV, Haelen, the Netherlands

${ }^{\mathrm{b}}$ Values followed by the same letters within a column are not significantly different at $P=0.05$

${ }^{c}$ Inoculated with $2 \times 10^{4}$ spores $\mathrm{ml}^{-1}$ water. Each value is the average of two replicates of 12 leaflets ( 3 leaflets $\times 2$ leaves $\times 2$ plants)

${ }^{\mathrm{d}}$ Inoculated with $4 \times 10^{3}$ spores ml ${ }^{-1}$ water. Each value is the average of three replicates of 12 or 24 leaflets $(3$ leaflets $\times 4$ leaves $\times 1$ plants or 3 leaflets $\times 4$ leaves $\times 2$ plants)

${ }^{\mathrm{e}}$ Inoculated with $10^{4}$ spores $\mathrm{ml}^{-1}$ in $0.1 \%$ agar. Each value is an average of five replicates of 12 leaflets $(3$ leaflets $\times 4$ leaves $\times 1$ plant $)$ ${ }^{\mathrm{f}} \sum\left(Y_{i} / s_{i}^{2}\right) / \sum\left(1 / s_{i}^{2}\right)$ 
Acknowledgments We thank Dr. Suhardi (Indonesian Ornamental Plants Research Institute, IOPRI) and Dr. E. Sofiari (Indonesian Vegetables Research Institute, IVEGRI) for providing the Alternaria solani isolate, and D. Geurtsen and A. Hermsen for their assistance in the glasshouse. Financial support was provided by the Royal Netherlands Academy of Arts and Sciences in the framework of the Scientific Programme Indonesia-Netherlands.

\section{References}

Banerjee MK, Chhabra ML, Saini PS (1998) Responses of tomato cultivars to Alternaria blight. Test Agrochem Cult 19:50-51

Barksdale TH (1969) Resistance of tomato seedlings to early blight. Phytopathology 59:443-446

Bonde R (1929) Physiological strains of Alternaria solani. Phytopathology 19:533-548

Foolad MR, Ntahimpera N, Christ BJ, Lin GY (2000) Comparison of field, greenhouse, and detached-leaflet evaluations of tomato germ plasm for early blight resistance. Plant Dis 84:967-972

Gardner RG (1988) NC EBR-1 and NC EBR-2 early blight resistant tomato breeding lines. HortScience 23:779-781

Gardner RG (1990) Greenhouse disease screen facilitates breeding resistance to tomato early blight. HortScience 25:222-223

Gardner RG, Shoemaker PB (1999) "Mountain Supreme" early blightresistant hybrid tomato and its parents, NC EBR-3 and NC EBR-4. HortScience 34:745-746

Henning RG, Alexander LJ (1959) Evidence of existence of physiologic races of Alternaria solani. Plant Dis Rep 43:298-308

Kalloo G, Banerjee MK (1993) Early blight resistance in Lycopersicum esculentum Mill. transferred from L. pimpinellifolium (L.) Mill. and L. hirsutum f. glabratum Mull. Gartenbauwissenschaft 58:238239
Locke SB (1948) A method for measuring resistance to defoliation diseases in tomato and other Lycopersicon species. Phytopathology 38:937-942

Locke SB (1949) Resistance to early blight and Septoria leaf spot in the genus Lycopersicon. Phytopathology 39:829-836

Nash AF, Gardner RG (1988) Tomato early blight resistance in a breeding line derived from Lycopersicon hirsutum PI 126445. Plant Dis 72:206-209

O'Leary DJ, Shoemaker PB (1983) Components of resistance for tomato early blight. Phytopathology 73:803

Pandey KK, Pandey PK, Kallo G, Banerjee MK (2003) Resistance to early blight of tomato with respect to various parameters of disease epidemics. J Gen Plant Pathol 69:364-371

Payne RW, Harding SA, Murray DA, Soutar DM, Baird DB, Welham SJ, Kane AF, Gilmour AR, Thompson R, Webster R, Wilson GT (2002) GenStat for Windows, 6th edn. VSN, Oxford

Peralta IE, Knapp S, Spooner DM (2005) New species of wild tomatoes (Solanum Section Lycopersicon: Solanaceae) from northern Peru. Syst Bot 30:424-434

Poysa V, Tu JC (1996) Response of cultivars and breeding lines of Lycopersicon spp. to Alternaria solani. Can Plant Dis Surv 76:5-8

Rotem J (1966) Variability in Alternaria porrii f. sp. solani. Israel J Bot $15: 48-57$

Rotem J, Reichert I (1964) Dew - a principal moisture factor enabling early blight epidemics in a semiarid region of Israel. Plant Dis Rep 48:211-215

Sherf AF, MacNab AA (1986) Vegetable diseases and their control. Wiley, New York

Thirthamalappa, Lohithaswa HC (2000) Genetics of resistance to early blight (Alternaria solani Sorauer) in tomato (Lycopersicum esculentum L.) Euphytica 113:187-193

Vakalounakis DJ (1983) Evaluation of tomato cultivars for resistance to Alternaria blight. Ann Appl Biol 102:138-139

Vloutoglou I (1999) Evaluation of tomato cultivars and hybrids for resistance to Alternaria solani infection. Test Agrochem Cult 20:4849 